\title{
The Anaerobic Bacteriology of Intrapulmonary Infections in Kuwait
}

\author{
D. Panigrahia V.O. Rotimi ${ }^{b}$ T.D. Chugh ${ }^{b}$ S.C. Sanyal ${ }^{c}$ Rita Dhard \\ Tina Lis Varghese ${ }^{b}$ \\ aDepartment of Medical Laboratory Sciences, Faculty of Allied Health Sciences and Nursing, and \\ Departments of Microbiology, ${ }^{b}$ Health Sciences Center, Kuwait University, ${ }^{c} l b n$ Sina Hospital, and \\ ${ }^{\mathrm{d} A d a n}$ Hospital, Ministry of Health, Kuwait
}

\section{Key Words}

Anaerobic bacteria - Intrapulmonary infection

\begin{abstract}
Objective: The primary objective of this study was to ascertain the association of anaerobic bacteria in intrapulmonary infections and their susceptibility pattern to commonly prescribed antibiotics. Methods: One hundred clinical samples (85 broncho-alveolar lavage and 15 lung abscess aspirates) from suspected intrapulmonary infection cases were investigated in order to determine the role of anaerobic bacteria in these infections. The anaerobic bacterial isolates were identified by using the Vitek Anaerobic Card System and conventional methods. Susceptibility of these isolates was determined by Etest method against eight commonly prescribed antibiotics. Results: A total of 42 anaerobes were isolated, of which Prevotella spp. were the commonest isolates, made up of $42.9 \%$ (18/42), followed by Peptostreptococcus spp. 33.3\% (14/42). Only two Bacteroides fragilis strains were isolated. All the isolates were sensitive to metronidazole, clindamycin, imipenem and meropenem; however, one Prevotella was resistant to piperacillin-tazobactam. The two $B$. fragilis isolates were susceptible to metronidazole, imipenem, meropenem and piperacillin-tazobactam, and one was found to be resistant to clindamycin. Conclusion: Overall, Prevotella spp. were found to be the predominant anaerobic bacteria
\end{abstract}

associated with intrapulmonary infections in Kuwait. All the commonly prescribed antibiotics had excellent in vitro activities against nearly all the isolates.

Copyright ( 92001 S. Karger AG, Basel

\section{Introduction}

Anaerobic bacteria are recognized causative pathogens involved in aspiration pneumonia and its suppurative complications, lung abscess and empyema. In recent years, with the advent of antibiotics, the bacteriology of intrapulmonary infections has changed [1]. In the preantibiotic era, Streptococcus pneumoniae was the predominant causative pathogen of empyema. However, since the advent of penicillin and other $\beta$-lactam antibiotics, its prevalence in this disease has dropped significantly to only about $10 \%$ of all cases. In its place anaerobes have now become the major bacterial pathogen associated with intrapulmonary infections [2-5]. In an earlier study reported by Bartlett et al. [2] anaerobic bacteria were associated with empyema in $79 \%$ of cases studied. Their isolates included Fusobacterium nucleatum, Bacteroides melaninogenicus, Bacteroides fragilis and gram-positive anaerobic and microaerophilic cocci in that order of frequency. After changes in taxonomy of anaerobic bacteria, Marina et al. [6] retrospectively analysed the results of pleuropulmonary specimens processed between 1976 and 1993. They found $F$. nucleatum, non-pigmented Prevotella,

\section{KARGER \\ Fax +4161306 1234 \\ E-Mail karger@karger.ch \\ www.karger.com

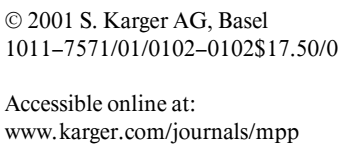

Prof. D. Panigrahi

Department of Medical Laboratory Sciences

Faculty of Allied Health Sciences and Nursing, Health Sciences Center, Kuwait University PO Box 31470, 90805 Sulaibikhat (Kuwait)

Tel. +965 483 3631, Fax +965 483 0937, E-Mail Debadatta@kuc01.kuniv.edu.kw 
Peptostreptococcus and members of the $B$. fragilis group to be the prevalent anaerobes associated with intrapulmonary infections. They isolated 3.0 anaerobes per pleural fluid specimen compared to 2.1 isolates per specimen isolated by Bartlett et al. [2]. In another retrospective study, Civen et al. [7] reported similar bacterial isolates from cases of empyema at a frequency of 3.5 isolates per specimen.

The treatment of patients with intrapulmonary infection has usually included administration of antibiotics, supportive care and drainage. Antibiotic selection is simplified when the diagnosis is established by gram staining and culture identification followed by antimicrobial susceptibility results [8]. Anaerobes are increasingly becoming resistant to $\beta$-lactams due to $\beta$-lactamase production and other mechanisms, as reported from different parts of the world including Kuwait [9, 10]. Quinolones are reported to be inactive or marginally active against anaerobes [9]. Recently, Rotimi et al. [11] reported highly metronidazole-resistant Bacteroides spp. isolated from 3 patients from Kuwait. These reports have made antibiotic therapy in suspected anaerobic intrapulmonary infections more complicated. Hence, detailed antimicrobial susceptibility testing must be carried out to guide the proper antibiotic therapy. In the present study, we report the isolation of anaerobic bacteria associated with intrapulmonary infections in Kuwait as well as their antimicrobial susceptibility to eight frequently prescribed anti-anaerobic antimicrobial agents.

\section{Materials and Methods}

A total of 100 intrapulmonary samples, of which 85 were broncho-alveolar lavage (BAL) and 15 aspirated pus from lung abscess, obtained from 100 patients were investigated over a period of 14 months from July 1997 to September 1998. Their ages ranged from 23 to 58 years with a mean of 42.3 years; 73 were males and 2 females. Fifteen patients had lung abscess as secondary to aspiration pneumonia. Of the remaining 85 patients, 20 were diagnosed with lung cancer, 30 were obvious cases of aspiration pneumonia and the remaining 35 were empyema cases. The samples were collected in sterile airtight containers and transported to the Anaerobic Laboratory in the Department of Microbiology, Faculty of Medicine within $1 \mathrm{~h}$ of collection for immediate processing. In the laboratory, all these specimens were cultured onto a set of selective and non-selective media: Brucella agar (Difco, Detroit, Mich., USA) supplemented with $5 \%$ horse blood, vitamin $\mathrm{K}(10 \mu \mathrm{g} / \mathrm{ml})$, hemin $(5 \mu \mathrm{g} / \mathrm{ml})$ and gentamicin $(75 \mu \mathrm{g} / \mathrm{ml})$ and plain Brucella agar plus $5 \%$ horse blood without supplements. A metronidazole disk $(5 \mu \mathrm{g})$ was placed on the surface of the inoculated agar plates. The plates were then incubated in the anaerobic jar (Oxoid Ltd., Basingstoke, UK) at $37^{\circ} \mathrm{C}$ for $48 \mathrm{~h}$ and examined for any growth. All plates without visible growth were further reincubated for 5 days. Representative colonies were chosen and subcultured for pure growth and then identified by the Vitek
Anaerobic Card System (bioMerieux, Vitek Inc., Hazelwood, Mo., USA) and combined with conventional identification methods [12].

Susceptibility of the anaerobic isolates was determined by estimating the minimum inhibitory concentrations (MICs) of metronidazole, clindamycin, imipenem, meropenem, cefoxitin, cefoperazone, ceftizoxime and piperacillin-tazobactam using Etest (AB Strips Biodisk, Solna, Sweden). Briefly, a suspension of the bacteria was made in brain-heart infusion broth to meet a $0.5 \mathrm{McF}$ arland turbidity standard which was then used to inoculate Wilkins-Chalgren agar (Unipath, Basingstoke, UK) supplemented with 7\% horse blood. Etest strips were then placed on the inoculated plates and incubated in the anaerobic jars at $37^{\circ} \mathrm{C}$ for $48 \mathrm{~h}$. The MIC was taken as the point of interception of the elliptical zone of inhibition across the strip. Interpretative criteria for susceptibility break points $(\mu \mathrm{g} / \mathrm{ml})$ recommended by the National Committee for Clinical Laboratory Standards [13] were followed in determining which strain was sensitive or resistant. B. fragilis ATCC 25285 was used in each run as a control to assess the reliability of the method and antimicrobial potency. Anaerobiosis was controlled by a nutrient agar plate of $\mathrm{Pseu}$ domonas aeruginosa and a chemical indicator placed inside each jar. The MICs less than or equal to the breakpoint were considered susceptible. Organisms inhibited by MICs greater than the breakpoint were considered resistant.

\section{Results}

A total of 42 anaerobic bacteria were isolated from 100 intrapulmonary samples at an isolation rate of 0.42 organisms per specimen. The aerobic bacterial isolates were $S$. pneumoniae, Haemophilus influenzae, and Klebsiella pneumoniae. Of the anaerobic isolates, Prevotella spp. were the commonest isolates, representing $42.9 \%$ (18/42) followed by Peptostreptococcus spp., 33.3\% (14/42). However, of the 42 isolates, Peptostreptococcus micros was the single most common anaerobic species, which accounted for $14(33.3 \%)$ of all strains. This was followed by $P r$. intermedia, 10 out of 42 (42\%), Fusobacterium nuclea-

Table 1. Distribution of anaerobic bacterial isolates from intrapulmonary samples

\begin{tabular}{lrc}
\hline Organism & $\begin{array}{c}\text { Number } \\
(\mathrm{n}=42)\end{array}$ & Percent \\
\hline Prevotella spp. & & \\
$\quad$ Pr. intermedia & 10 & 23.8 \\
$\quad$ Pr. melaninogenica & 5 & 11.9 \\
$\quad$ Pr. denticola & 3 & 7.1 \\
Subtotal & 18 & 42.9 \\
\hline P. micros & 14 & 33.3 \\
F. nucleatum & 8 & 19.1 \\
B. fragilis & 2 & 4.8 \\
Total & 42 & 100 \\
\hline
\end{tabular}


Table 2. Susceptibility pattern of the 42 anaerobic isolates to 8 antimicrobial agents at accepted breakpoints

\begin{tabular}{|c|c|c|c|c|c|c|c|c|c|}
\hline \multirow[t]{2}{*}{ Organism } & \multicolumn{9}{|c|}{ Percentage of strains susceptible to } \\
\hline & $\begin{array}{l}\text { strains } \\
\text { tested }\end{array}$ & $\begin{array}{l}\text { metro- } \\
\text { nidazole }\end{array}$ & $\begin{array}{l}\text { clinda- } \\
\text { mycin }\end{array}$ & imipenem & meropenem & cefoxitin & cefoperazone & ceftizoxime & $\begin{array}{l}\text { piperacillin- } \\
\text { tazobactam }\end{array}$ \\
\hline Pr. intermedia & 10 & 100 & 100 & 100 & 100 & 100 & 70.0 & 80.0 & 90.0 \\
\hline Pr. melaninogenica & 5 & 100 & 100 & 100 & 100 & 100 & 60.0 & 80.0 & 100 \\
\hline Pr. denticola & 3 & 100 & 100 & 100 & 100 & 100 & 66.6 & 100 & 100 \\
\hline P. micros & 14 & 100 & 100 & 100 & 100 & 100 & 83.3 & 83.3 & 83.3 \\
\hline F. nucleatum & 8 & 100 & 100 & 100 & 100 & 87.5 & 87.5 & 100 & 100 \\
\hline Total & 40 & 100 & 100 & 100 & 100 & 97.5 & 74 & 89.1 & 95.1 \\
\hline
\end{tabular}

tum, 8 out of 42 (19\%), Pr. melaninogenica, 5 out of 42 (12\%) and Pr. denticola, 3 out of 42 (7\%). Only two strains of $B$. fragilis were isolated in this study (table 1).

The susceptibility pattern of the isolates is shown in table 2. All the Prevotella and Peptostreptococcus spp. were susceptible to metronidazole, clindamycin, imipen$\mathrm{em}$, meropenem and cefoxitin with $\mathrm{MIC}_{90} \mathrm{~S}$ of 0.5 and $1.0 \mu \mathrm{g} / \mathrm{ml}, 0.5$ and $1.0 \mu \mathrm{g} / \mathrm{ml}, 0.25$ and $0.25 \mu \mathrm{g} / \mathrm{ml}, 0.25$ and $0.25 \mu \mathrm{g} / \mathrm{ml}$, and 4 and $8 \mu \mathrm{g} / \mathrm{ml}$, respectively. Only one Prevotella and two $P$. micros were resistant to piperacillintazobactam (MIC $>64 \mu \mathrm{g} / \mathrm{ml}$ ). The $F$. nucleatum isolates were susceptible to metronidazole, clindamyin, imipenem, meropenem, ceftizoxime and piperacillin-tazobactam with $\mathrm{MIC}_{90} \mathrm{~s}$ of $0.25,1.0,0.25,0.25,1.5$, and $2 \mu \mathrm{g} / \mathrm{ml}$, respectively. The two isolates of $B$. fragilis were susceptible to metronidazole (MIC $=0.5 \mu \mathrm{g} / \mathrm{ml}$ ) and piperacillintazobactam $(\mathrm{MIC}=4 \mu \mathrm{g} / \mathrm{ml})$ and one was resistant to clindamycin $(\mathrm{MIC}=16 \mu \mathrm{g} / \mathrm{ml})$.

\section{Discussion}

Anaerobic bacteria are relatively common in a variety of pulmonary infections and are especially often involved in aspiration pneumonia and its complications. Investigation of such conditions can be problematic because of the method required to obtain proper specimens, e.g., transthoracic aspiration is no longer used in general medicine. The alternative, open lung biopsy aspiration, is not ethically justified. However, double-lumen brush border protected BAL is now commonly used for this purpose as the least dangerous of the invasive methods available [14-16].

The most commonly encountered anaerobes in intrapulmonary infections reported from the industrialized countries are the pigmented Prevotella spp. with a predominance of Prevotella intermedia and Prevotella mela- ninogenica, non-pigmented Prevotella, spp., F. nucleatum, Peptostreptococcus spp. and Bacteroides spp. [1-3, 6, 7]. Our findings in the present study are essentially similar to these reports. However, the gram-positive anaerobic cocci, i.e. P. micros, was the predominant anaerobe in the intrapulmonary infections studied by us. The isolation rate of these organisms was 0.43 anaerobe per clinical specimen. This isolation rate is considerably lower than that reported by others $[2,7]$. A number of factors might have been responsible for this discrepancy, including the inevitable delay in transportation of specimens to the laboratory and unavoidable brief exposure to air on the bench. It is also conceivable that infections other than those traditionally associated with anaerobic bacteria were investigated. It is noteworthy that all 15 lung abscesses yielded anaerobes on culture. Finding only 2 isolates of $B$. fragilis in these infections is consistent with other reports, which indicate that it does not commonly occur in intrapulmonary infections, whereas black pigmented Prevotella spp. and anaerobic cocci are quantitatively and qualitatively predominant.

Antimicrobial agents have played an important role in the therapy of both aerobic and anaerobic bacterial infections. In contrast to aerobic bacterial lung infections, few treatment options are available for anaerobic infections because of their intrinsic resistance to many antibiotics. The development of resistance to antimicrobial agents has made the reporting of susceptibility of anaerobes less predictable and increased the demand on laboratories to provide such susceptibility data. Disk diffusion tests for example are generally not applicable for susceptibility testing of anaerobes because the gradient profile around the disk changes over time. A large zone of inhibition may only reflect slow growth of anaerobes and not their actual susceptibility. Thus, the Etest, which has been evaluated by several workers and found suitable for testing anaer-

\footnotetext{
$\overline{104} \quad \overline{\text { Med Principles Pract 2001;10:102-105 }}$
} 
obes $[17,18]$, is the current recommended susceptibility testing methodology [13]. The agar dilution method can also be used, but this method is time-consuming and tedious to perform. In the present study, metronidazole, clindamycin, imipenem, meropenem and, to some extent, piperacillin-tazobactam had excellent in vitro activity against all the isolates at concentrations far below the achievable serum levels following normal parenteral and oral dosage of these antibiotics. Cefoxitin, a second generaton cephamycin, and the newer generation cephalosporins, cefoperazone and ceftizoxime, reportedly active against aerobes, were less active than the traditional drugs often used for anaerobic infections. Hence, these latter drugs should be used with caution when considering drugs for empirical therapy of anaerobic pleuropulmonary infections.

Over the years, most of the anaerobes and particularly the Bacteroides spp. have displayed remarkable stability to the in vitro activity of metronidazole, the most widely used drug against anaerobic infections. However, recently Rotimi et al. [11] have reported metronidazole-resistant $B$. fragilis isolated from intra-abdominal infections from 3 patients in Kuwait. Although the overall resistance rate in Kuwait is very low, $1 \%$ [10], it is therefore important that the clinical laboratories be alert to potential emergence of resistant strains in their hospitals. The Prevotella spp., Peptostreptococcus spp. and Fusobacterium spp. were all sensitive to clindamycin, imipenem and meropenem. Similar isolates in an earlier study in Kuwait by Rotimi et al. [10] also showed similar susceptibility profiles for all the above antibiotics except clindamycin. In their report, 10\% of Prevotella spp. and 17\% of Fusobacterium spp., mainly from intra-abdominal infections and soft tissue infections, were resistant to clindamycin by the agar dilution method.

\section{Conclusion}

Prevotella spp. were found to be the dominant anaerobic bacterial isolates from intrapulmonary infections, but individually $P$. micros was the most common isolate. Metronidazole, a time-tested anti-anaerobic agent, and the carbapenems had excellent in vitro activity against anaerobic bacteria. These agents and piperacillin-tazobactam could be used as alternatives to clindamycin, often used in the treatment of intrapulmonary anaerobic infections, because of their low MIC values and other outstanding pharmacokinetic properties.

\section{Acknowledgement}

This study was funded by Kuwait University, Research Administration grant NPM 034.

\section{References}

1 Bartlett JG: Anaerobic bacterial infections of the lung and pleural space. Clin Infect Dis 1993; 16(suppl 4):S248-255.

2 Bartlett JG, Gorbach SL, Thadepalli H, Finegold SM: Bacteriology of empyema. Lancet 1974;81:329-331.

3 Bartlett JG, Finegold SM: Anaerobic infection of the lung and pleural space. Am Rev Respir Dis 1974; 110:56-77.

4 Varkey B, Rose D, Kutty CPK, Politis J: Empyeme thoracis during a ten-year period: Analysis of 72 cases and comparison to a previous study (1952 to 1967). Arch Intern Med 1981; 141:1771-1776.

5 Alfageme I, Munoz F, Pena N, Umbria S: Empyema of the thorax in adults. Chest 1993;103: 839-843.

6 Marina M, Strong CA, Civen R, Molitoris E, Finegold SM: Bacteriology of anaerobic pulmonary infections: Preliminary report. Clin Infect Dis 1993;16(suppl 4):S256-262.

7 Civen R, Jousimies-Somer H, Marina M, Borenstein L, Shah H, Finegold SM: A retrospective review of cases of anaerobic empyema and update of bacteriology. Clin Infect Dis 1995;20(suppl 2):S224-229.
8 Bartlett GJ: Lung abscess and necrotizing pneumonia; in Gorbach SL, Bartlett JG, Blacklow NR (eds): Infection Disease, ed 2. Philadelphia, Saunders, 1998, pp 635-639.

9 Edinie ML, Jacobs MR, Appelbaum PC: Activities of tatifloxacin compared to those of seven other agents against anaerobic organisms. Antimicrob Agents Chemother 1998;42:24592462.

10 Rotimi VO, Mokaddas EM, Jamal WY, Khodakhast FB, Verghese TL, Sanyal SC: Susceptibility of 497 clinical isolates of gram-negative anaerobes to trovafloxacin and eight other antibiotics. J Chemother 1999;11:349-356.

11 Rotimi VO, Khoursheed M, Brazier JS, Jamal WY, Khodakhast FB: Bacteroides species highly resistant to metronidazole: An emerging clinical problem? Clin Microbiol Infect 1999;5: 166-169.

12 Summanen P, Baron EJ, Citron DM, Strong CA, Wexler HM, Finegold SM: Wordworth Anaerobic Bacteriology Manual, ed 5. Belmont, Star Publishing Company, 1993, pp 1149.
13 National Committee for Clinical Laboratory Standards: Methods for antimicrobial susceptibility testing for anaerobic bacteria. Approved standard M11-A4, vol 17, No 22. Villanova, NCCLS, 1997.

14 Thorpe JE, Baughman RP, Frame PT, Wesseler TA, Staneck JL: Bronchoalveolar lavage for diagnosis acute bacterial pneumonia. J Infect Dis 1987; 155:855-861.

15 Kahn FW, Jones JM: Diagnosing bacterial respiratory infection by bronchoalveolar lavage. J Infect Dis 1987;155:862-869.

16 Lorch DG Jr, John JF Jr, Tomlinson JR, Miller KS, Sahn SA: Protected transbronchial needle aspiration and protected specimen brush in the diagnosis of pneumonia. Am Rev Respir Dis 1987;136:565-569.

17 Bolmstrom A: Susceptibility testing of anaerobes with Etest. Clin Infect Dis 1993;16(suppl 4):367-370.

18 Schieven BC, Massey VE, Lannigan R, Hussain $\mathrm{Z}$ : Evaluation of susceptibility of anaerobic organisms by the Etest and the reference agar dilution method. Clin Infect Dis 1995; 20(suppl 2):S337-338. 